\title{
Cells and mediators from pharyngeal secretions in infants with acute wheezing episodes
}

\author{
F.P. Counil*, B. Lebel**, M. Segondy+, C. Peterson++, M. Voisin*, \\ J. Bousquet**, B. Arnoux**
}

Cells and mediators from pharyngeal secretions in infants with acute wheezing episodes. F.P. Counil, B. Lebel, M. Segondy, C. Peterson, M. Voisin, J. Bousquet, B. Arnoux. (C)ERS Journals Ltd 1997.

ABSTRACT: An acute wheezing episode is the most common feature of severe lower respiratory tract infection during infancy. Respiratory syncytial virus (RSV) is the major causative agent.

In order to study inflammation during acute wheezing episodes in infants, we wanted to assess the feasibility and contribution of induction of pharyngeal secretions.

We therefore compared inflammatory markers in the pharyngeal secretions of 27 infants suffering from acute wheezing episodes with an RSV infection (RSV+) and 18 infants suffering with acute wheezing episodes without RSV infection (RSV-). Pharyngeal secretions were recovered by physiotherapy using isotonic saline. The safety of the procedure was carefully checked. Pharyngeal secretions were homogenized with dithiothreitol. Total cells and eosinophils were counted and levels of eosinophil cationic protein (ECP) and histamine were measured.

Induction of pharyngeal secretion was always well tolerated. Eosinophils were present in five RSV+ and seven RSV-patients. ECP levels were not significantly different between the groups. Histamine levels after protein adjustment were significantly increased in $\mathrm{RSV}+$ patients $(\mathrm{p}<0.01)$ in comparison to $\mathrm{RSV}$ - patients.

In this study, we have shown, that pharyngeal secretion can be safely recovered from infants suffering from acute wheezing episodes, and that it can be analysed for enumeration of inflammatory cells and measurement of inflammatory mediators. Eur Respir J 1997; 10: 2591-2595.

\begin{abstract}
*Service de Pédiatrie, and **INSERM U 454, Hôpital Arnaud de Villeneuve, Montpellier, France. +Service de Virologie, Hôpital St Eloi, Montpellier, France. ++Pharmacia AB Diagnostics, Uppsala, Sweden.
\end{abstract}

Correspondence: B. Arnoux,

INSERM U 454

Hôpital Arnaud de Villeneuve

34295 Montpellier Cedex 5

France

Keywords: Acute wheezing episodes infants

pharyngeal secretion

Received: January 291997

Accepted after revision July 211997
An acute wheezing episode is the most common severe lower respiratory tract infection in infancy. During epidemics, over $80 \%$ of cases may be caused by a respiratory syncytial viral (RSV) infection [1]. Although symptoms may become severe, most infections are selflimited, and improvement usually occurs within several days $[2,3]$. Approximately $2 \%$ of infants under 2 yrs of age require hospitalization [4]. In severe acute wheezing episodes, necrosis of the respiratory epithelium, excessive production of mucus, and lymphocytic infiltration result in oedema, dense plugs of debris and subsequent bronchiolar obstruction. The role of eosinophil activation in RSV infection needs to be clarified. It has been observed that nasal or pharyngeal secretions recovered from infants suffering from RSV infection have increased eosinophil cationic protein (ECP) levels. A correlation between ECP levels and severity was noted in one study [5], but ECP levels were found to be similar to those of healthy infants in two other studies $[6,7]$. However, no study has yet examined inflammatory markers in the pharyngeal secretions of infants.

A study was carried out during a viral infection episode in 45 infants suffering from acute wheezing episodes requiring hospitalization, and pharyngeal secretions were recovered by physiotherapy. The safety of the procedure was carefully monitored. Inflammatory cells were counted and inflammatory markers were measured in order to differentiate inflammation in infants suffering from acute wheezing episodes with RSV infection (RSV+) or without RSV infection (RSV-).

\section{Materials and methods}

\section{Study population}

Fourty five infants (1-24 months of age) experiencing acute wheezing episodes severe enough to require hospitalization were included in the study from December to March. Informed consent was obtained from all parents. The diagnosis of acute wheezing episodes was based on symptoms, i.e. tachypnoea, dyspnoea, prolonged expiration and wheezing. Patients with pneumonia on chest radiography were excluded [8], as were patients with bronchopulmonary dysplasia, congenital heart disease or cystic fibrosis. Antibiotic use was not an exclusion criterion. Children with secondary pulmonary condensation or bacterial superinfection were not excluded. At the time of admission, all infants were treated with inhaled $\beta_{2}$-agonist bronchodilators. 


\section{Virus identification}

RSV was identified in nasopharygeal secretions by direct immunofluorescence assay (IFA) using monoclonal antibodies to RSV (clone 18B2; Argène, Varilhes, France) and by viral isolation onto MRC-5 cell cultures in $25 \mathrm{~cm}^{2}$ tissue culture flasks [9]. IFA was also used for identification of influenza virus A (clone IA52; Marne la Coquette, France) and influenza virus B (clone IB82; Sanofi Diagnostics Pasteur, Marne la Coquette France), parainfluenza virus type 1 (clones 11-H9-13; Argène) type 2 (clone 128-33; Argène) and type 3 (clone 5-12; Argène) and adenovirus (Monofluokit adenovirus; Sanofi Diagnostics Pasteur). Other viruses, such as rhinoviruses, cytomegalovirus (CMV) or herpes simplex virus (HSV), were identified by the production of their characteristic cytopathic effect in MRC-5 cultures. HSV typing was performed by immunofluorescence, using monoclonal antibodies.

\section{Sampling of pharyngeal secretions}

Samples of pharyngeal secretions were collected on the first day of hospitalization. Sampling of pharyngeal secretion was carried out using chest physiotherapy. After a 20 min nebulization period with prewarmed $\left(25^{\circ} \mathrm{C}\right)$ isotonic saline (DeVilbiss 65 ultrasonic nebulizer), chest physiotherapy was performed. A nasal lavage with 5 $\mathrm{mL}$ of sterile isotonic saline solution was first performed (twice), removed by suction and discarded. Acceleration of expiratory flow technique was induced by a skilled paediatric physiotherapist. Pharyngeal secretions were then collected by gentle nasopharyngeal aspiration using a sterile kit (Aspirateur de mucosité, Vygon, Ecouen, France). All samples were collected between 07:00 and 08:00 h after a $4 \mathrm{~h}$ fasting period. All samples were immediately treated for analysis.

\section{Safety of pharyngeal secretion sampling}

The safety of the pharyngeal secretion production was carefully studied: respiratory frequency, cardiac frequency with electrocardiography (ECG) (Physiogard SM785; Wissembourg, France, USA), and pulse oximetry (Nellcor, N180; Hayward, CA, USA) were monitored throughout the procedure.

\section{Analysis of pharyngeal secretions}

The volume of the secretion sample was measured, then incubated with dithiothreitol (DTT, 10-7 M; Sigma Chemical Co., St Louis, MO, USA). The volume of DTT used ranged from $100 \mu \mathrm{L}$ to $1 \mathrm{~mL}$ according to the volume of the sample $(1 / 1 \mathrm{v} / \mathrm{v})$. The sample was agitated in a vortex mixer for $30 \mathrm{~s}$ and the mixture was then drawn up into a plastic pipette and expelled repeatedly $(20 \times)$ to obtain a fluid sample. Phosphate-buffered saline (PBS) solution ( $\mathrm{pH} 7.4)$ was added and the sample was mixed using a vortex mixer for another $30 \mathrm{~s}$.

Total cell counts, and viability were determined using a haemocytometer. Viability was assessed using trypan blue exclusion. The cell suspension $(70 \mu \mathrm{L})$, adjusted to $1 \times 10^{6}$ cells $\cdot \mathrm{mL}^{-1}$, was centrifuged in a Shandon 2 cytocentrifuge (5 min at $500 \mathrm{rpm}$ ). One slide was stained with Diff Quick® (RAL, Paris, France) for differential cell counts on at least 200 cells. A second slide was stained with the monoclonal antibody EG2 in order to distinguish activated eosinophils [10] (Kabi-Pharmacia Diagnostics, Uppsala, Sweden). A third slide was stained with toluidine blue to assess metachromatic cells.

The supernatant was stored at $-20^{\circ} \mathrm{C}$ until analysis. The protein content of the fluid sample was measured with BCA protein assay (Pierce, Rockford, IL, USA). Histamine was measured using enzyme immunoassay [11] (Immunotech, Marseille, France) according to the instructions given on the package insert. ECP was measured using radioimmunoassay [12] (Kabi-Pharmacia Diagnostics) following the manufacturer's instructions. Histamine and ECP levels were expressed as concentration of mediator per unit of volume $\left(\mu \mathrm{g} \cdot \mathrm{mL}^{-1}\right)$ or per milligram of protein $\left(\mu \mathrm{g} \cdot \mathrm{mg}^{-1}\right)$ of the pharyngeal secretion.

\section{Statistical analysis}

Results were expressed as median values with interquartile range. Differences between groups were analysed using nonparametric tests (Mann-Whitney U-test). Correlation analysis was performed using Spearman's rank correlation. Statistical analysis was performed using StatView 4.1 software.

\section{Results}

\section{Demographic characteristics of the patients}

Patients were then divided into two groups on the basis of the presence of RSV. Demographic characteristics of the patients are presented in table 1. There was no difference in median age between RSV+ and RSVpatients, both when the total population was considered and when males and females were considered separately. Cytomegalovirus was also detected in four RSV+ patients. In the RSV- group, four patients were found to be positive for: rhinovirus $(n=1), \operatorname{HSV}_{-1}(n=1)$, influenza virus $A(n=1)$ and influenza virus $B(n=1)$.

\section{Safety of the procedure}

Collection of pharyngeal secretions performed following isotonic saline inhalation was well tolerated in all cases. In particular, none of the infants presented tachycardia over 180 beats $\cdot \mathrm{min}^{-1}$, or bradycardia below 60 beats $\cdot \mathrm{min}^{-1}$. Transcutaneous oxygen saturation was always over $80 \%$.

Table 1. - Demographic data of patients studied

\begin{tabular}{ccc}
\hline Bronchiolitis & $\begin{array}{c}\text { Pts } \\
\mathrm{n}\end{array}$ & $\begin{array}{c}\text { Age } \\
\text { months }^{\#}\end{array}$ \\
\hline RSV+ & 27 & $4.5(2.0-11.0)$ \\
Males & 16 & $5.0(3.5-11.5)$ \\
Females & 11 & $4.0(1.0-9.0)$ \\
RSV- & 18 & $8.5(4.0-13.0)$ \\
Males & 13 & $5.0(4.0-12.0)$ \\
Females & 5 & $12.0(5.0-15.0)$ \\
\hline
\end{tabular}

\#: median, and interquartile range in parenthesis. Pts: patients; RSV: respiratory syncytial virus; +: positive; -: negative. 


\section{Total and differential cell counts}

The volume of pharyngeal secretion recovered was similar in both groups (table 2). Total and differential cell counts of the pharyngeal secretion were not statistically different between the two groups (table 2), or between males and females. Metachromatic cells were not recovered from pharyngeal secretion samples. Only five patients in the RSV+ group and seven patients in the RSV-group had eosinophils in pharyngeal secretion eosinophils (fig. 1), although, EG2 staining was always negative.

\section{Proteins and mediators}

The protein content of the fluid was similar in the two groups (median (interquartile range) $2.7(1.2-4.8)$ and $3.0(0.9-7.1) \mathrm{mg} \cdot \mathrm{mL}^{-1}$ of secretion in RSV+ and RSV-group, respectively). ECP and histamine were measurable in all samples. ECP levels were not significantly different between the two groups, and no significant differences were noticed between males and females. Histamine levels were found to be similar when expressed per unit of volume of recovered pharyngeal secretion $\left(\mu \mathrm{g} \cdot \mathrm{mL}^{-1}\right)$ (fig. $\left.2 \mathrm{a}\right)$, but were significantly increased in $\mathrm{RSV}+$ patients when expressed per unit of protein $(\mu \mathrm{g} \cdot \mathrm{mg}$ protein $^{-1} ; \mathrm{p}<0.01$, Mann-Whitney U-test) (fig. 2b).

Table 2. - Sputum parameters of the patients studied

\begin{tabular}{llrl}
\hline $\begin{array}{l}\text { Sputum } \\
\text { parameter }\end{array}$ & Bronchiolitis & & \\
\hline Volume mL & RSV+ & 1.5 & $(1.0-2.0)$ \\
& RSV- & 1.0 & $(0.8-1.5)$ \\
TCC & RSV+ & 2.9 & $(1.7-5.0)$ \\
$\times 10^{-5}$ cells·mL-1 & RSV- & 1.7 & $(0.7-7.0)$ \\
Macro \% & RSV+ & 30.0 & $(14.7-62.0)$ \\
& RSV- & 28.5 & $(14.0-50.5)$ \\
PMN \% & RSV+ & 67.0 & $(37.7-84.5)$ \\
& RSV- & 67.0 & $(47.5-86.6)$ \\
Eosin \% & RSV+ & 0.0 & $(0.0-0.9)$ \\
& RSV- & 0.0 & $(0.3-1.0)$ \\
\hline
\end{tabular}

Data are presented as median, and interquartile range in parenthesis. TCC: total cell count of nonsquamous cells; Macro: macrophages; PMN: polymorphonuclear cells; Eosin: eosinophils; RSV: respiratory syncytial virus; +: positive; -: negative.

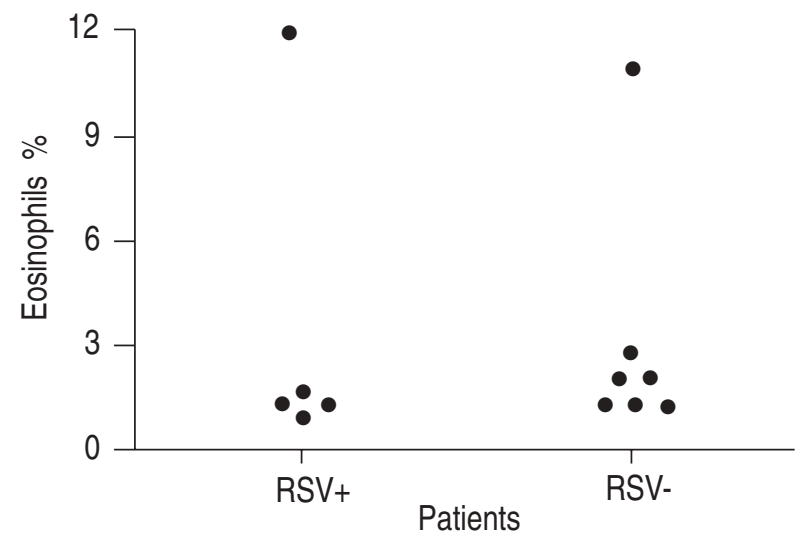

Fig. 1. - Percentage of eosinophils in pharyngeal secretions from RSV+ $(n=27)$ and RSV- $(n=18)$ patients with acute wheezing episodes. RSV: respiratory syncytial virus; +: positive; -: negative; $\bullet$ one patient. Only those patients with eosinophils in the pharyngeal secretions are presented in the diagram.
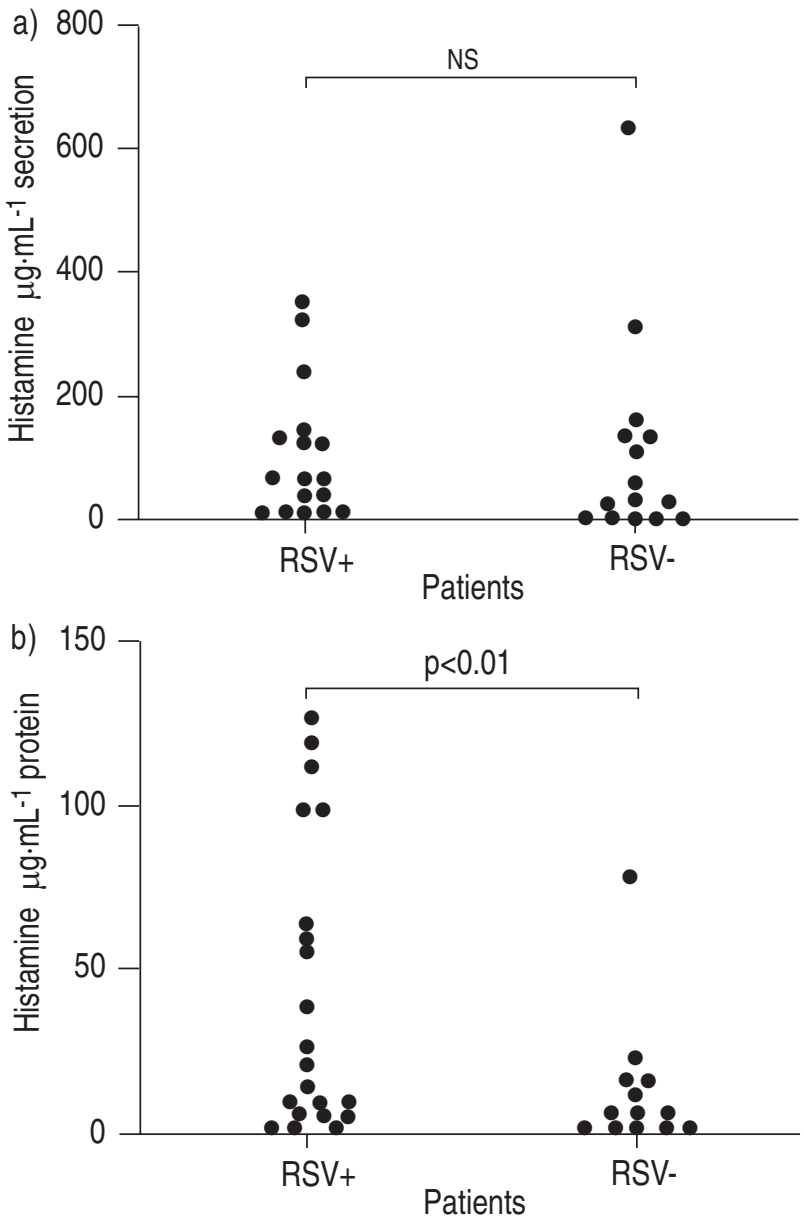

Fig. 2. - Histamine levels in pharyngeal secretion from RSV+ $(n=27)$ and RSV- $(n=18)$ patients with an acute wheezing episodes. a) $\mu \mathrm{g}$ of histamine per $\mathrm{mL}$ of pharyngeal secretion; b) $\mu \mathrm{g}$ of histamine per $\mathrm{mg}$ of proteins. RSV: respiratory syncytial virus; +: positive; -: negative; ๑: one patient. NS: nonsignificant. Only those patients with histamine in the pharyngeal secretions are presented in the diagram.

There were no significant correlations between the amounts of ECP and eosinophils (number or percentage) present in pharyngeal secretion, or with the age of the patients.

\section{Discussion}

This study has shown that pharyngeal secretions can be safely recovered in infants suffering from acute wheezing episodes and can be analysed for the measurement of inflammatory cells and inflammatory mediators. It was found that eosinophil activation was not increased in infants suffering from RSV acute wheezing episodes in comparison to those suffering from acute wheezing episodes due to other viruses. On the other hand, histamine levels after protein adjustment were increased in $\mathrm{RSV}+$ patients. The diagnosis of RSV infection was based on IFA in combination with RSV isolation in cell culture. IFA is a very sensitive method in the detection of RSV in respiratory samples: $87-92.6 \%$ were reported $[13,14]$. In our laboratory, the sensitivity of the detection is $89 \%$ (unpublished data). Moreover, the sensitivity of the diagnostic method has been enhanced with two consecutive cell cultures. The proportion of RSV- children (55\%) in the present study is similar to 
a recent multicentric French study, showing an RSV+ prevalence of $58 \%$ in a group of infants with acute wheezing episodes [15]. We have analysed all potential relationships between the inflammatory parameters and clinical status, i.e. hospital stay, duration of the disease, type of treatment, values of blood gas, blood differential cell counts, presence of oxygen therapy and type of drug treatment (data not shown). No relationships were observed.

Sputum induction has been proposed as a noninvasive tool for assessing airway inflammation in adult asthmatic subjects $[16,17]$. However, the authors have used nebulization of hypertonic saline to induce sputum. Hypertonic saline can cause bronchoconstriction [18, 19], and such a procedure cannot be used in infants. Moreover, all infants studied have a sufficient production of pharyngeal secretion with isotonic saline. On the other hand, humidification of the airways using isotonic saline significantly increases tracheobronchial clearance in patients with bronchial hypersecretion [20]. Nebulization of isotonic saline is a common supportive treatment for viral acute wheezing episodes [1]. In the present study, this procedure was followed by chest physiotherapy in order to collect an "induced" pharyngeal secretion. This procedure was well tolerated and can be routinely carried out by a paediatric chest physiotherapist. In infants, the noninvasive collection of respiratory tract secretions usually involves a simple nasopharyngeal aspiration $[5,6,21]$. However, these studies do not sample the secretions from the bronchial tree. In the present study, we attempted to collect lower airways secretions and to minimize nasopharyngeal contamination, a nasal lavage being carried out just before the secretion collection. In the absence of a specific marker of nasal secretion, the inevitable contamination by upper airways secretions cannot be assessed.

In the present study, total and differential cell counts of nonsquamous cells were similar to those reported in adults [16, 22]. The percentages were similar to those of cells observed in broncholalveolar lavage (BAL) of infants with RSV infection [23]. Few eosinophils were detected in the pharyngeal secretion, with no significant differences between the two groups. Only one subject in each group exhibited a high percentage of this cell type. The differential on the remaining cells was not different between the two groups. The absence of EG2positive cells is probably due to the DTT treatment of the pharyngeal secretion [24]. The low number of eosinophils in the pharyngeal secretion was consistent with the absence of eosinophils in the bronchial wall observed in an autopsy series in RSV acute wheezing episodes [25]. Moreover, the peripheral blood eosinophil count from patients with acute wheezing episodes was found to be similar to that in the peripheral blood of control subjects [26].

In nasopharyngeal secretions from patients with RSV infection, eosinophil activation has been suggested, since higher levels of ECP [5] and sulphidopeptide leukotrienes [27] were found compared to those in RSVpatients. Moreover, high ECP levels $\left(>50 \mathrm{ng} \cdot \mathrm{mL}^{-1}\right)$ were predictive of short-term development of wheezing [5]. The present results conflict with these studies, since ECP concentrations were similar in the two groups. The results of the present study are consistent with those re- ported by others $[6,7]$. In the latter study, no statistical difference in ECP/albumin ratio was found between $34 \mathrm{RSV}+$ and $27 \mathrm{RSV}$ - infants with respiratory tract infection. However, we did not observe a difference in the ECP level of pharyngeal secretions between males and females, as described for the group of patients from El Salvador [7].

The histamine data must be considered carefully because of the method of expressing the results. The pharyngeal secretion obtained after chest physiotherapy is humidified by nebulization of saline solution, which may result in dilution of the sample. It is, therefore, important to normalize the concentration of histamine $\left(\mu \mathrm{g} \cdot \mathrm{mL}^{-1}\right)$ according to the protein concentration of the sample $\left(\mathrm{mg} \cdot \mathrm{mL}^{-1}\right)$ [28]. In this study, histamine levels were not elevated in pharyngeal secretions, but the recovery of the secretions was carried out slightly after the acute phase of infection [28]. However, the presence of tryptase, the major neutral proteinase of human mast cells, which is released in parallel with histamine during degranulation [29], was reported in sputum sampled during exacerbation of lung inflammation [30], and in BAL fluid of infants with RSV acute bronchiolitis [31]. It is also hypothesized that histamine is released from basophils via an immunoglobulin E (IgE) mediated process induced by paramyxoviruses [32]. The present data are in agreement with these results observed during respiratory tract viral infection. The presence of histamine was detected in both groups, a higher level being found in RSV+ patients. A relationship between histamine and RSV was observed using an animal model [33]. Elevated plasma levels of histamine have also been observed in patients during acute bronchiolitis [34].

This study demonstrates that samples of pharyngeal secretions from infants hospitalized with bronchial hypersecretion can be obtained safely. Our results suggest mast cell activation during respiratory syncytial virus positive acute wheezing episodes (histamine release), whereas eosinophil activation seems to be less specific and less prominent in the pathology of this disease. Moreover, the discordant results observed between cellular and mediator composition of the pharyngeal secretion (i.e. the absence of eosinophils and mast cells but the presence of ECP and histamine), may be related to increased permeability of the lung parenchymal tissue. Such analysis of the pharyngeal secretion in infants, performed during the acute phase of the disease, could be useful in evaluating the role of histamine and other inflammatory mediators in the development and the evolution of other inflammatory lung diseases, such as asthma.

Acknowledgements: The authors thank the physiotherapist, C. Payet, for her kind assistance, and M. Campbell for reviewing the manuscript.

\section{References}

1. Wohl M. Bronchiolitis in children. In: Diseases of the Bronchioles. New York, Raven Press Ltd, 1994; pp. 397-407.

2. McLean K. The pathology of acute bronchiolitis: a study of its evolution. I. The exudative phase. Aust Ann Med 1956; 5: 254-265. 
3. McLean K. The pathology of acute bronchiolitis: a study of its evolution. II: The repair phase. Aust Ann Med 1957; 6: 29-35.

4. Navas LE, Wang V, de Carvallo F, Robinson J. Pediatric investigators collaborative network on infections in Canada: improved outcome of respiratory syncytial virus infection in high-risk hospitalized population of Canadian children. J Pediatr 1992; 121: 348-354.

5. Garofalo R, Kimpen JL, Welliver RC, Ogra PL. Eosinophil degranulation in the respiratory tract during naturally acquired respiratory syncytial virus infection. $J$ Pediatr 1992; 120: 28-32.

6. Sigurs N, Bjarnason R, Sigurbergsson F. Eosinophil cationic protein in nasal secretion and in serum and myeloperoxidase in serum in respiratory syncytial virus bronchiolitis: relation to asthma and atopy. Acta Paediatr 1994; 83: 1151-1155.

7. Colocho Zelaya EA, Örvell O, Strannegard Ö. Eosinophil cationic protein in nasopharyngeal secretions and serum of infants infected with respiratory syncytial virus. Pediatr Allergy Immunol 1994; 5: 100-106.

8. Wohl M, Chernick V. Bronchiolitis: state of the art. Am Rev Respir Dis 1978; 118: 759-776.

9. Johnstson SL, Siegel CL. Evaluation of direct immunofluorescence, enzym immunoassay, centrifugation culture, and conventional culture for the detection of respiratory syncytial virus. J Clin Microbiol 1990; 28: 2394-2397.

10. Tai PC, Spry CJ, Peterson C, Venge P, Olsson P. Monoclonal antibodies distinguish between storage and secreted forms of eosinophil cationic protein. Nature 1984; 309: 182-184.

11. Morel A, Delaage M. Radioimmunoassay for histamine: application to histamine release. J Allergy Clin Immunol 1988; 82: 646-654.

12. Peterson CG, Enander I, Nystrand J, Anderson AS, Nilsson L, Venge A. Radioimmunoassay of human eosinophil cationic protein (ECP) by an improved method: establishment of normal levels in serum and turnover in vivo. Clin Exp Allergy 1991; 21: 561-567.

13. Dominguez EA, Taber LH, Couch RB. Comparison of rapid diagnostic techniques for respiratory syncytial and influenza A virus respiratory infections in young children. J Clin Microbiol 1993; 31: 2286-2290.

14. Miller H, Milk R, Diaz-Mitoma F. Comparison of the VIDAS RSV assay and the Abbott Testpack RSV with direct immunofluorescence for detection of respiratory syncytial virus in nasopharyngeal aspirates. $J$ Clin Microlbiol 1993; 31: 1336-1338.

15. Grimprel E, François P, Olivier C, et al. Epidémiologie clinique et virologique de la bronchite du nourisson: enquête national multicentrique. Mèd Mal Infect 1993; Spécial: 844-850.

16. Pin I, Freitag AP, O'Byrne PM, et al. Changes in the cellular profile of induced sputum after allergeninduced asthmatic responses. Am Rev Respir Dis 1992; 145: 1265-1269.

17. Fahy JV, Liu J, Wong H, Boushey HA. Cellular and biochemical analysis of induced sputum from asthmatic and from healthy subjects. Am Rev Respir Dis 1993; 147: 1126-1131.

18. Belcher NG, Murdoch RD, Dalton N, et al. A comparison of mediator and catecholamine release between exercise- and hypertonic saline-induced asthma. Am Rev Respir Dis 1988; 137: 1026-1032.

19. Araki H, Sly PD. Inhalation of hypertonic saline as a bronchial challenge in children with mild asthma and normal children. JAllergy Clin Immunol 1989: 84: 99-107.

20. Conway JH, Fleming JS, Perring S, Holgate ST. Humidification as an adjunct to chest physiotherapy in aiding tracheobronchial clearance in patients with bronchiectasis. Respir Med 1992; 86: 109-114.

21. Welliver RC, Kaul TN, Ogra PL. The appearance of cell-bound IgE in respiratory-tract epithelium after respiratory syncytial virus infection. $N$ Engl J Med 1980; 303 (21): 1198-1202.

22. Fahy JV Liu J, Boushey HA. Comparison of samples collected by sputum induction and bronchoscopy from asthmatic and healthy subjects. Am J Respir Crit Care Med 1995; 152: 53-58.

23. Everard ML, Swarbrick A, Wrightam M, et al. Analysis of cells obtained by bronchial lavage of infants with respiratory syncytial virus infection. Arch Dis Child 1994; 71: 428-432.

24. Popov T, Gottschalk R, Kolendowicz R, Dolovich J, Powers P, Hargreave FE. The evaluation of a cell dispersion method of sputum examination (see Comments). Clin Exp Allergy 1994; 24: 778-783.

25. Neilson K, Yunis E. Demonstration of respiratory syncytial virus in an autopsy series. Pediatr Pathol 1990; 10: 491-502.

26. Garofalo R, Dorris A, Ahlstedt S, Welliver R. Peripheral blood eosinophil cationic protein content of respiratory secretions in bronchiolitis: relationship to the severity of disease. Pediatr Allergy Pulmonol 1994; 5: 111-118.

27. Garofalo R, Welliver RC, Ogra PL. Concentrations of $\mathrm{LTB}_{4}, \mathrm{LTC}_{4}, \mathrm{LTD}_{4}$ and $\mathrm{LTE}_{4}$ in bronchiolitis due to respiratory syncytial virus. Pediatr Allergy Immunol 1991; 2: 30-37.

28. Welliver RC, Wong DT, Sun M, Middleton E, Vaughan RS, Ogra PL. The development of respiratory syncytial virus-specific IgE and the release of histamine in nasopharyngeal secretion after infection. $N$ Engl J Med 1981; 15: 841-846.

29. Schwartz LB, Lewis RA, Austen KF. Tryptase from human mast cells: purification and characterization. $J$ Biol Chem 1981; 256: 11939-11943.

30. Fahy JV, Kim KW, Liu J, Boushey HA. Prominent neutrophilic inflammation in sputum from subjects with asthma exacerbation. J Allergy Clin Immunol 1995; 95: 843-852.

31. Everard ML, Fox G, Walls AF, et al. Tryptase and IgE concentrations in the respiratory tract of infants with acute bronchiolitis. Arch Dis Child 1995; 72: 64-69.

32. Sanchez-Legrand F, Smith FS. Interaction of paramyxoviruses with human basophils and their effect on histamine release. J Allergy Clin Immunol 1989; 84: 538-546.

33. Sorden SD, Castleman WL. Virus-induced increases in bronchiolar mast cells in Brown Norway rats are associated with both local mast cell proliferation and increases in blood mast cell precursors. Lab Invest 1995; 73: 197-204.

34. Skoner DP, Fireman P, Caliguiri L, Davis H. Plasma elevations of histamine and a prostaglandin metabolite in acute wheezing episodes. Am Rev Respir Dis 1990; 142: 359-364. 